\title{
RESPONSABILIDADE EDUCACIONAL: CONCEPÇÕES DIFERENTES E RISCOS IMINENTES AO DIREITO À EDUCAÇÃO
}

\author{
SALOMÃo BARRos Ximenes*
}

RESUMO: O ensaio analisa o debate atual sobre responsabilidade educacional e sua relação com a qualidade do ensino, tomando como referência a agenda de reformas do direito à educação e as diferentes concepções em disputa. Retoma as resoluções da Conferência Nacional de Educação e os projetos de lei sobre o assunto, analisando-os com base na atual definição jurídica de responsabilidade aplicável à educação.

Palavras-chave: Responsabilidade educacional. Padrão de qualidade do ensino. Direito à Educação. Legislação do ensino.

\section{EDUCATIONAL RESPONSIBILITY: DIFFERENT CONCEPTIONS AND IMMINENT RISKS TO THE RIGHT TO EDUCATION}

ABSTRACT: The essay examines the current debate on educational responsibility and its relationship to the quality of education. Makes reference to the reform agenda of the right to education and the different conceptions under dispute. It systematizes the resolutions of the National Conference on Education and the bills on the subject, analyzing them based on the current legal definition of responsibility applicable to education.

Key words: Educational responsibility. Quality standard of education. Right to education. Legislation of education.

\section{RESPONSABILITÉ EDUCATIONNELLE: CONCEPTIONS DIFFERENTES ET RISQUES IMMINENTS AU DROIT A L'EDUCATION}

RÉSUMÉ: L'essai analyse le debat actuel sur la responsabilite educationnelle et sa relation avec la qualite de l'enseignement, en prenant pour reference le programme de reformes du droit a l'education et les differentes conceptions en dispute. l'article reprend les resolutions de la Conference Nationale de l'Education et les projets de loi sur ce theme, en les analysant comme base dans l'actuelle definition juridique de responsabilite applicable a l'education.

Mots-clés: Responsabilité éducationnelle. Norme de qualité de l'enseignement. Droit à l'Education. Législation de l'enseignement. * Doutorando em Direito do Estado pela Universidade de São Paulo (USP) e coordenador de progra-
ma na Ação Educativa: Assessoria, Pesquisa e Informação. E-mail: salomaoximenes@gmail.com 


\section{Introdução}

$\mathrm{P}$ aralelamente à atribulada tramitação do Projeto de Lei n. 8.035/10 sobre o novo Plano Nacional de Educação (PNE) no Congresso Nacional, encontra-se em discussão, com menos alarde e quase nenhuma participação social, um conjunto de propostas de regulamentação da chamada "responsabilidade educacional".

Luiz Carlos de Freitas chama a atenção para esse processo, reconhecendo que "a ideia de responsabilizar os gestores educacionais pela qualidade da educação vem de longa data, mas no Brasil, em termos legais, começa a ganhar forma nesta década", sendo impulsionada pelo que denomina "reformas educacionais empresariais" (Freitas, 2011).

Por outro lado, a necessidade de aprovação de uma Lei de Responsabilidade Educacional (LRE) foi afirmada nas deliberações da Conferência Nacional de Educação (Conae) (Brasil, 2010), cujas resoluções são claramente favoráveis à redução da participação do setor privado e de sua lógica mercadológica na educação. Na Conae foi tratada como proposição complementar ao PNE, que resguardaria a eficácia do plano ao estipular punições para gestores públicos omissos no cumprimento dos deveres constitucionais e legais relacionados ao ensino. Não à toa, o projeto (PL n. 8.039) do governo sobre o assunto foi proposto pelo ex-presidente Lula simultaneamente ao que trata do PNE, em dezembro de 2010.

Ocorre que na Câmara dos Deputados já hibernavam algumas propostas de regulamentação da responsabilidade educacional, sem maiores perspectivas quanto à sua real apreciação e aprovação. A disposição do governo em discutir a matéria fez a pauta avançar no Legislativo, dando novo ânimo aos seus defensores. ${ }^{1}$ Em outubro de 2011, seguindo exemplo do já ocorrido com o PNE, foi constituída Comissão Especial sobre a LRE, decisão política que retirou da Comissão de Educação e Cultura a apreciação do assunto. Na Comissão Especial a matéria pode ser votada em caráter terminativo, sem necessidade de passar pelo Plenário.

Catorze projetos, entre eles o PL n. 8.039, foram reunidos para apreciação em conjunto, tendo como referência a mais antiga das proposições, o PL n. 7.420, de 2006, de autoria da deputada Raquel Teixeira, que, de acordo com sua ementa, "dispõe sobre a qualidade da educação básica e a responsabilidade dos gestores públicos na sua promoção" (Brasil, 2006).

O presente ensaio chama a atenção para os riscos e potencialidades presentes nesse processo, tomando como referência o direito à educação e a delimitação atual do debate representada pelos projetos reunidos para deliberação em conjunto na Comissão Especial. 
Neste ensaio, partimos do reconhecimento de que há uma agenda de juridificação da educação, apoiada por amplos setores que intervêm na política educacional, com diferentes visões, e que os temas responsabilidade e qualidade estão na fronteira desse processo. Independentemente do sucesso de cada uma das proposições, a pauta está colocada e nada indica que este debate perderá força no próximo período.

Em seguida, retomamos as definições jurídicas atuais de responsabilidade jurídica e educacional presentes na legislação, analisando as alterações propostas pelos projetos de lei em discussão, seus limites e as possibilidades não exploradas. Com isso, esperamos contribuir com uma adequada delimitação do debate, explicitando em que medida a responsabilização vem sendo defendida, no sentido de avançar na proteção jurídica do direito à educação pública e em que medida traz consigo uma agenda oculta de promoção da lógica mercantil na educação.

\section{Responsabilidade e qualidade como agendas de juridificação do direito à educação}

A decisão da Câmara de reunir para deliberação conjunta um amplo escopo de projetos e as diferentes concepções em disputa em cada um deles tiveram como consequência a ampliação do enfoque do debate sobre responsabilidade educacional, quando considerado o sentido jurídico até então adotado na legislação, incorporando ao mandato da Comissão Especial legislar sobre nada menos que a qualidade da educação. Conforme apresentado na Tabela 1, a ampliação do enfoque não está apenas no projeto de Raquel Teixeira, mas na maioria dos que estão em discussão.

Instituiu-se na Comissão Especial da LRE a polêmica aproximação entre o objeto da responsabilidade educacional e a definição jurídica de qualidade, ampliando-se os riscos já constatados quando analisado isoladamente o projeto que a encabeça: "já há na presente versão [do PL n. 4.020/06] posicionamentos que propõem a responsabilização como um processo que envolve a fiscalização da obtenção de metas de progressão acadêmica pela escola, medidas a partir de testes padronizados" (Freitas, 2011).

Na verdade, como demonstra o quadro-resumo apresentado, pelo menos outras três proposições - PLs n. 1.680/07, 413/11 e 450/11 - preveem que o não atingimento das metas de desempenho acadêmico, estabelecidas para cada rede de ensino, levaria ao dever de adotar medidas específicas nos campos da gestão e do financiamento. No caso de persistir o baixo desempenho ou de não serem adotadas tais ações, os gestores e agentes públicos seriam responsabilizados nas esferas civil, política e penal. 


\section{Tabela 1}

Projetos, autores e síntese do conteúdo das matérias sob análise da Comissão Especial da Lei de Responsabilidade Educacional

\begin{tabular}{|c|c|}
\hline Proposição e Autor & Síntese do Conteúdo \\
\hline $\begin{array}{l}\text { Igual teor: } \\
\text { PL 4.020/06, de } \\
\text { Raquel Teixeira } \\
\text { (PSDB/GO) } \\
\text { PL 413/11, de } \\
\text { Gastão Vieira } \\
\text { (PMDB/MA) } \\
\text { PL 450/11, de } \\
\text { Thiago Peixoto } \\
\text { (PSD/GO) }\end{array}$ & $\begin{array}{l}\text { - Define o padrão nacional de qualidade como a universalização } \\
\text { do ensino em tempo integral e a garantia de determinados insu- } \\
\text { mos e do custoaluno/qualidade; } \\
\text { - Determina que a qualidade deve ser aferida em processo nacio- } \\
\text { nal de avaliação; } \\
\text { - Estipula um sistema de acompanhamento dos resultados das } \\
\text { avaliações e das taxas de rendimento em cada ente federado, } \\
\text { determinando a elevação do gasto por aluno quando não se ob- } \\
\text { servem avanços; } \\
\text { - Condiciona as transferências voluntárias aos esforços dos entes } \\
\text { federados; } \\
\text { - Determina a responsabilidade dos gestores e agentes públicos } \\
\text { pelo descumprimento do previsto na lei, caracterizando as omis- } \\
\text { sões como crime de responsabilidade, infração político-administra- } \\
\text { tiva e ato de improbidade; }\end{array}$ \\
\hline $\begin{array}{l}\text { PL 1.680/07, de } \\
\text { Lelo Coimbra } \\
\text { (PMDB/ES) }\end{array}$ & $\begin{array}{l}\text { - Especifica o dever do Estado, programas de avaliação do magis- } \\
\text { tério, infraestrutura adequada e avaliação padronizada anual do } \\
\text { rendimento dos alunos; } \\
\text { - Define o padrão de qualidade como a melhoria contínua nas } \\
\text { médias dos alunos aferidas na avaliação nacional e nas taxas de } \\
\text { rendimento, estabelecendo metas para cada rede de ensino e deter- } \\
\text { minando a elevação do gasto por aluno nos casos em que não se } \\
\text { observem avanços; } \\
\text { - Determina que a União deve equalizar a capacidade de dispên- } \\
\text { dio dos entes federados, através de transferências voluntárias; } \\
\text { - Proíbe transferências voluntárias aos entes federados que des- } \\
\text { cumpram a lei; } \\
\text { - Determina a responsabilidade dos gestores e agentes públicos } \\
\text { pelo descumprimento do previsto na lei, caracterizando as omis- } \\
\text { sões como crime de responsabilidade, infração político-administra- } \\
\text { tiva e ato de improbidade. }\end{array}$ \\
\hline
\end{tabular}




\begin{tabular}{|c|c|}
\hline $\begin{array}{l}\text { PL 8.039/10, do } \\
\text { Poder Executivo }\end{array}$ & $\begin{array}{l}\text { - Inclui na Lei da Ação Civil Pública a modalidade ação civil pú- } \\
\text { blica de responsabilidade educacional; } \\
\text { - Delimita como objeto da ação as obrigações de fazer e não fazer } \\
\text { previstas na legislação e nos convênios, ajustes e termos assina- } \\
\text { dos entre os entes federados; } \\
\text { - Delimita que não cabe ação de responsabilidade para exigir o } \\
\text { cumprimento de metas de qualidade aferidas por institutos ofi- } \\
\text { ciais de avaliação. }\end{array}$ \\
\hline $\begin{array}{l}\text { Igual teor: } \\
\text { PL 247/07, de } \\
\text { Sandes Júnior } \\
\text { (PP/GO) }\end{array}$ & $\begin{array}{l}\text { - Inclui entre as infrações administrativas previstas no Estatuto da } \\
\text { Criança e do Adolescente (ECA) a omissão de professores e gesto- } \\
\text { res em notificar ao Conselho Tutelar situações de faltas reiteradas, } \\
\text { evasão e maus-tratos; e a omissão dos pais ou responsáveis em } \\
\text { efetuar a matrícula na idade obrigatória; }\end{array}$ \\
\hline $\begin{array}{l}\text { PL } 600 / 07, \text { de } \\
\text { Carlos Abicalil } \\
\text { (PT/MT) }\end{array}$ & $\begin{array}{l}\text { - Define como ato de improbidade a não aplicação dos recursos } \\
\text { vinculados à manutenção e desenvolvimento do ensino (MDE), } \\
\text { ou sua aplicação irregular, prevendo que a reincidência leva à ine- } \\
\text { legibilidade no termos da chamada Lei da Ficha Limpa; } \\
\text { - Determina a redução das transferências voluntárias da União } \\
\text { em valor semelhante ao que deixou de ser obrigatoriamente apli- } \\
\text { cado em MDE. }\end{array}$ \\
\hline $\begin{array}{l}\text { PL 1.256/07, de } \\
\text { Marcos Montes } \\
\text { (DEM/MG) }\end{array}$ & $\begin{array}{l}\text { - Inclui na LDB a previsão de crime, punível com detenção, por } \\
\text { omissão dos pais ou responsáveis em efetuar a matrícula no en- } \\
\text { sino fundamental e acompanhar e corrigir aspectos relacionados } \\
\text { à sua vida escolar. }\end{array}$ \\
\hline $\begin{array}{l}\text { PL } 8.042 / 10, \text { de } \\
\text { Jovair Arantes } \\
\text { (PTB/GO) }\end{array}$ & $\begin{array}{l}\text { - Estende a autoria do crime de abandono intelectual, previsto no } \\
\text { Código Penal, aos que deixem de prover instrução à criança ou } \\
\text { adolescente sob sua guarda ou tutela. }\end{array}$ \\
\hline $\begin{array}{l}\text { PL 1.747/11, de } \\
\text { Teresa Surita } \\
\text { (PMDB/RR) }\end{array}$ & $\begin{array}{l}\text { - Institui na LDB os critérios e procedimentos para o processo } \\
\text { nacional de avaliação do rendimento escolar na educação básica, } \\
\text { prevendo avaliações periódicas a partir do } 2^{\circ} \text { ano do ensino fun- } \\
\text { damental, critérios de validação e publicidade dos resultados por } \\
\text { escola, entre outras diretrizes. }\end{array}$ \\
\hline $\begin{array}{l}\text { PL 1.915/11, de } \\
\text { Carlos Souza } \\
\text { (PP/AM) }\end{array}$ & $\begin{array}{l}\text { - Institui na LDB o "índice de desenvolvimento escolar", dispondo } \\
\text { sobre sua composição e forma de divulgação em meio eletrônico e } \\
\text { em cada escola, em local de fácil visibilidade para a comunidade. }\end{array}$ \\
\hline
\end{tabular}




\begin{tabular}{|l|l|}
\hline $\begin{array}{l}\text { PL 2.604/11, de } \\
\text { Thiago Peixoto } \\
\text { (PSD/GO) }\end{array}$ & $\begin{array}{l}\text { - Institui em lei específica o Sistema Nacional de Avaliação da } \\
\text { Educaçáo Básica (Saeb), determinando procedimentos, critérios } \\
\text { de validação e publicidade dos resultados por escola, entre outras } \\
\text { diretrizes. }\end{array}$ \\
\hline $\begin{array}{l}\text { PL 3.066/11, de } \\
\text { Romero Rodrigues } \\
\text { (PSDB/PB) }\end{array}$ & $\begin{array}{l}\text { - Institui na LDB o dever de divulgação do índice-síntese, obtido } \\
\text { em processo de avaliação nacional, pelo próprio estabelecimento } \\
\text { de ensino, por meio de painel ou cartaz, em local de fácil visua- } \\
\text { lização na entrada do prédio escolar. }\end{array}$ \\
\hline $\begin{array}{l}\text { PL 2.417/11, de } \\
\text { (PTB/PR) }\end{array}$ & $\begin{array}{l}\text { - Dispõe sobre Arranjos de Desenvolvimento da Educação (ADE), } \\
\text { determinando que a União priorize a assistência técnica e financei- } \\
\text { ra aos entes federados que assim se articulem. }\end{array}$ \\
\hline
\end{tabular}

Se algumas das medidas previstas podem parecer interessantes, principalmente a previsão de elevação do gasto por aluno, outras acabam punindo duplamente a coletividade, e não exatamente os responsáveis, como fica evidente na hipótese de suspensão das transferências voluntárias aos entes federados que não alcancem as metas acadêmicas ou não respeitem as demais disposições.

Risco maior, no entanto, advém da possibilidade de responsabilizar por ato de improbidade administrativa, em razão do não cumprimento das metas, não apenas os gestores, mas a totalidade dos agentes públicos, no que se inclui o magistério. Isso está implícito na própria definição da Lei de Improbidade Administrativa, conforme será comentado adiante.

Portanto, não se podem subestimar os impactos potenciais dessas propostas na definição do regime jurídico do direito à educação e do padrão de qualidade e, especificamente, no papel que as políticas de avaliação nacional ocuparão na gestão dos sistemas de ensino. Como aponta Brooke (2006), experiências de responsabilização direta dos educadores já vêm sendo adotadas em algumas redes de ensino, em grande medida com a roupagem de bonificação de professores e escolas com base no desempenho, numa espécie de responsabilização às avessas, que apresenta graves riscos à ideia de universalidade e igualdade na educação. Com a eventual implantação da responsabilidade vinculada a metas de desempenho, no entanto, a tendência é a ampliação da pressão produtivista sobre professores e escolas, estimulando estratégias de resistência e a adoção de mecanismos de diferenciação na rede pública.

Além disso, diferentemente do PNE, naturalmente transitório, uma LRE pode vir a se constituir como uma nova base da política educacional, inclusive 
influenciando os futuros planos, ao consolidar no longo prazo essa perspectiva hegemônica de qualidade.

Poder-se-ia contestar, baseando-se na lição de Oliveira e Araújo (2005), que esta hegemonia já está dada no cotidiano das políticas e do debate educacional,tendo como maior expressão o Plano de Desenvolvimento da Educação (PDE), ancorado nos compromissos assumidos em relação ao Índice de Desenvolvimento da Educação Básica (Ideb). No entanto, não se pode perder de vista a função de legitimação promovida pelo Direito e também sua função promocional, características do intervencionismo estatal através das políticas públicas, cuja principal espécie normativa é a "lei de incentivo" (Bobbio, 2007).

Com a função de legitimação, transforma-se uma política de governo - como é o caso do Ideb e do PDE - em política de Estado, passando-se a determinar a conduta de todas as esferas de governo e das administrações futuras. Esse é o sentido de outro bloco de projetos em discussão na Câmara, que pouco tem a ver com responsabilidade em sentido estrito: PLs n. 1.747/11, 1.915/11 e 2.604/11, todos propostos no último ano. Mais que hegemonia, exige-se previsibilidade e segurança jurídica para tais políticas.

Com a função promocional, complementarmente, ajustam-se as expectativas sociais através da premiação direta ou indireta daqueles que colaboram, o que não elimina, registre-se, a sempre necessária presença de normas repressivas a serem aplicadas ou meramente apresentadas. Este é o caso específico das normas de responsabilização.

Relevante para as políticas públicas educacionais, nesse sentido, é o efeito de ajuste voluntário de condutas promovido pelas normas promocionais, complementado pela possibilidade de aplicação das normas de responsabilização, produzidas para serem aplicadas residualmente.

Esse modelo jurídico-normativo, caracterizado pela difusão de normas promocionais, ganha força no contexto de reação ao neoliberalismo, no qual percebemos uma "onda de juridificação" (Grau, 2010) das relações escolares e das políticas públicas. De braços dados com a juridificação, o fenômeno da "judicialização da educação" (Cury \& Ferreira, 2010; Silveira, 2010) amplia a influência do Poder Judiciário nos rumos das políticas educacionais.

A definição do conteúdo jurídico da qualidade do ensino é uma das principais fronteiras desse processo de juridificação, uma "nova dimensão de luta pelo direito à educação" (Oliveira \& Araújo, 2005), que requer a regulamentação do padrão constitucional de qualidade "num conjunto de indicadores passível de exigência judicial" (idem, ibid., p. 21), determinando-se com isso a noção de responsabilidade 
a ser implementada: Que qualidade se objetiva alcançar? Que qualidade poderia ser apropriada pela linguagem jurídica? Que qualidade seria exigível na justiça? Estas são algumas das questões que povoam o debate.

Cury e Ferreira (2010), tomando em conta a necessidade de dar parâmetros objetivos de avaliação da qualidade do ensino ao Judiciário, defendem a regulamentação, em norma nacional, do inciso IX do artigo $4^{\circ}$ da LDB, com a adoção dos parâmetros presentes no Custo Aluno/Qualidade Inicial. Estes seriam tomados como indicadores de qualidade a serem complementados pelo "resultado dos índices dos testes padronizados aplicados aos alunos" (Ferreira \& Cury, op. cit., p. 86). Pautam assim a necessidade de definição de insumos e resultados exigíveis.

Oliveira (2006, p. 72), por outro lado, defende a definição de indicadores mais compreensivos da qualidade, que sejam incorporados como parte do direito à educação: "Apesar da centralidade dos insumos, não se pode restringir a ideia de qualidade apenas a eles. Há que avançar no debate de duas outras dimensões, a dos resultados e a dos processos". O autor defende, particularmente, "a dimensão dos processos que ocorrem na escola, posto que não são indiferentes, como supõem as abordagens estritamente econômicas" (p. 73), numa proposição que dialoga com a necessidade de respeito aos direitos humanos na educação e com a exigência de formação humanista e para a cidadania.

São justamente as abordagens economicistas, criticadas por Oliveira, que pressionam pela definição de qualidade e responsabilização com base predominantemente em resultados de testes, reduzindo o direito à educação, e suas dimensões coletiva, igualitária e processual, à ideia de direito à aprendizagem, de viés fortemente individualista e centrado no resultado, capaz de criar oposições entre o estudante e o sistema, compreendidos como cliente e empresa. Nesta perspectiva, o direito público à educação torna-se o direito privado do consumidor de produtos educacionais.

Assim se apresenta, com novas roupagens e novos atores, o histórico embate entre o projeto inacabado de escola pública estatal e republicana e os defensores da mercantilização da educação. Essa cisão se reflete de forma evidente nas disputas de emendas ao novo PNE, mas também pode ser identificada nas "duas concepções de responsabilização em pauta" (Freitas, 2011).

É bem verdade, como alerta Freitas (op. cit.), que há a possibilidade dos projetos de lei serem profundamente modificados, ou mesmo de voltarem às gavetas do Legislativo. No entanto, como os temas "qualidade" e "responsabilidade" estão postos na agenda de juridificação, da qual nada parece indicar sua retirada, podemos tomá-los como expressão das questões em discussão no atual período, com os devidos cuidados. Independentemente do sucesso de cada uma das proposições, estas desde já indicam as tendências e as concepções em disputa. 


\section{Responsabilidade jurídica e seu regime específico em relação à educação: previsão atual e modificações propostas}

Para correta delimitação do debate, faz-se necessário retomar o(s) conceito(s) e o regime jurídico da responsabilidade geral e educacional já instituída no ordenamento jurídico brasileiro. Trata-se de desmistificar e afastar a ideia de que hoje vigoraria a absoluta irresponsabilidade educacional, ou seja, que autoridades, gestores e profissionais da educação não podem ser punidos por atos e omissões atentatórias ao direito à educação.

É bem verdade que há um sentimento de pouca responsabilização pela violação do direito à educação no país, que se confunde com a percepção das dificuldades em se exigir judicialmente o direito à educação, mas em ambos os casos não é correto dizer que isso se dá pela completa ausência de previsão legal.

Seria mais correto afirmar que o déficit de responsabilidade educacional tem diferentes origens, entre elas, os limites materiais e procedimentais presentes nas normas. Outros limites seriam o déficit de controle social e a má compreensão geral sobre o sentido da responsabilidade e sobre os sujeitos aos quais se aplica.

\section{Os sentidos da responsabilidade}

O termo "responsabilidade" comporta diferentes acepções no debate público educacional. Cury (2011, p. 3), em trabalho apresentado como subsídio às discussões no Fórum Nacional de Educação, assim o define, demonstrando de pronto um duplo significado:

Por responsabilidade deve-se entender a obrigação que pesa sobre um sujeito em satisfazer uma prestação (social) que lhe é positivamente atribuída. Cumprir encargos, desempenhar atribuições confiadas a um administrador público é uma obrigação que não sendo fielmente cumprida responde, e (é responsabilizado) por eventuais omissões e irregularidades.

Essa polissemia também está expressa no Documento Final da Conae (2010), no qual o termo aparece, juntamente com "corresponsabilidade", em 29 ocasiões. Na maior parte delas, no sentido definido por Cury (op. cit.), aludindo, no contexto da crítica à política educacional, ao debate sobre a necessidade de adequação e explicitação do regime constitucional de competências em matéria de ensino, ou ainda ao dever educacional do Estado e as atribuições dos diferentes entes federados.

Em apenas cinco ocasiões no Documento, "responsabilidade" significa punição pessoal por desrespeito às normas educacionais, sendo que na maior parte destas alude à necessidade de criação de uma Lei de Responsabilidade Educacional, desconsiderando as previsões hoje existentes. ${ }^{2}$ 
Segundo as resoluções do encontro, uma melhor definição das responsabilidades federativas passaria pela criação de um "Sistema Nacional Articulado de Educação" e pela regulamentação do regime de colaboração previsto na Constituição:

(...) a CF/1988 e a LDB/1996 atribuíram à União, aos estados, ao Distrito Federal e aos municípios a responsabilidade pela administração do sistema educacional brasileiro. Daí a exigência de um sistema nacional de educação articulado, norteado pela firme concepção da educação como direito humano fundamental, direito público e dever do Estado. Sua operacionalização não pode prescindir da regulamentação do regime de colaboração entre as instâncias federadas - o que, certamente, ensejará o estabelecimento de marcos teórico-conceituais na organização, na gestão e no real alcance do papel dos entes, por seu caráter descentralizado. (Brasil, 2010, p. 106-107)

Do ponto de vista do conceito jurídico, o termo responsabilidade, nesses casos, poderia ser substituído por "atribuição" ou "competência", que pode significar tanto dever de prestação material (ofertar determinado serviço público) como dever de legislar sobre determinado assunto.

Nesse sentido, há delimitação do papel de cada ente federado tanto na Constituição como na LDB, sobretudo após a Emenda Constitucional n. 14, de 1996, que promoveu a repartição de competências materiais pela oferta de cada etapa da educação básica e atribuiu à União "função redistributiva e supletiva, de forma a garantir equalização de oportunidades educacionais e padrão mínimo de qualidade do ensino mediante assistência técnica e financeira aos Estados, ao Distrito Federal e aos Municípios" (Constituição, art. 211, §1).

Apesar disso, e mesmo com as mitigações promovidas pelos fundos redistributivos, é profundo o desequilíbrio entre recursos e atribuições constitucionais, fruto da ausência de um efetivo regime de colaboração e de uma política de financiamento baseada no gasto-aluno, que desconsidera os custos reais de cada etapa e modalidade de ensino, como leciona Pinto (2007).

Os fatores relativos ao financiamento e às atribuições federativas estão diretamente relacionados ao debate político sobre os limites da responsabilidade jurídica pessoal dos administradores e agentes públicos (Cury, 2011), que é o tema por excelência de uma LRE. Essa relação de dependência entre responsabilidade e condições de realização está explícita nas resoluções da Conae:

(...) torna-se pertinente a criação de uma lei de responsabilidade educacional que defina meios de controle e obrigue os responsáveis pela gestão e pelo financiamento da educação, nos âmbitos federal, estadual, distrital e municipal, a cumprir o estabelecido nas constituições federal, estaduais, nas leis orgânicas municipais e distrital e na legislação pertinente e estabeleça sanções administrativas, cíveis e penais no caso de descumprimento dos dispositivos legais determinados, deixando claras as competências, os recursos e as responsabilidades de cada ente federado. (Brasil, 2010, p. 28) 
Haveria aí três propósitos para a LRE: i) explicitar e detalhar o regime de repartição de competências e atribuições de cada esfera estatal, aproximando-a do que seria a pretendida regulamentação do regime de colaboração; ii) definir os meios de verificação do cumprimento das atribuições legais e, em sentido mais restrito, definir os sujeitos responsáveis e iii) assegurar um regime de sanções pessoais mais efetivas para o descumprimento das determinações legais, capazes de fortalecer, segundo essa concepção, a implementação do direito à educação. ${ }^{3}$

Nessa linha de raciocínio, o grande valor de uma LRE seria tomar como exemplo a Lei de Responsabilidade Fiscal e "reunir, num só todo, os responsáveis e as responsabilidades dos entes federativos e dar consequência ao que determina o conjunto do ordenamento jurídico do país" (Cury, 2011, p. 11).

Por outro lado, e nesse ponto reside parte importante do debate sobre a abrangência esperada para uma futura LRE, da perspectiva específica do incremento das responsabilidades pessoais, através de normas repressivas, uma LRE não precisaria, necessariamente, dispor sobre matérias tão amplas nem instituir padrões nacionais vinculantes, ou seja, prescindiria de uma base equânime de responsabilização.

Essa possibilidade de dissociação entre responsabilidade e condições materiais só alimenta os riscos já identificados: pode-se chegar a uma LRE que desconsidere o aspecto do desequilíbrio e da insuficiência no financiamento e, fechando os olhos para essa questão de difícil resolução, concentre suas atenções nos resultados nos testes padronizados, e não nas condições de aprendizagem e funcionamento das escolas.

Esse problema central é identificado por Cury (op. cit., p. 15), que ressalta a importância de se regulamentar previamente o regime de colaboração educacional:

Contudo, se abstrairmos dos recursos obrigatórios que possuem uma via mais clara, se abstrairmos de lá onde se situa o direito público subjetivo, resta uma situação problemática. Trata-se da zona cinzenta que ainda paira sobre o regime de colaboração. As atribuições federativas devem ficar mais claras e específicas. A indefinição relativa a uma lei complementar e a postergação de sua proposição põe limites prévios a uma lei de responsabilidade educacional. Com o aclaramento trazido por essa lei complementar, que poderá dar mais sentido a um Sistema Nacional de Educação e sua decorrência em um Plano Nacional de Educação, uma lei de responsabilidade educacional ganhará consolidação e efetividade.

Por outro lado, a responsabilidade, no sentido jurídico mais preciso, é pura norma repressiva. Significa tão somente a possibilidade de enquadrar determinado ato ou omissão como passível de sanção ou reparação. Aplica-se tanto aos particulares, nas suas relações privadas, às empresas e instituições civis, quanto 
aos agentes públicos e ao Estado, através de sua personalidade jurídica. Manifestase, a depender da situação e dos sujeitos envolvidos, como responsabilidade civil, penal, administrativa, funcional ou política.

Uma LRE, nesse sentido, "emana de um conjunto de direitos já então definidos na Constituição e na Lei" (Gomes, 2008, p. 12), estes sim, com caráter promocional. Sua estrutura fundamental seria constituída por: bem jurídico-educacional protegido (p. ex., acesso universal à pré-escola), sujeito responsabilizável (p. ex., o prefeito), procedimento de apuração e sanção e/ou reparação. Nesse sentido:

Para que o conceito de responsabilidade educacional seja vivido, é preciso contar com o reconhecimento de três aspectos:

1 - A educação é um direito. (...).

2 - Se esse direito é subtraído de alguém, haverá responsáveis por atos e omissões.

3 - Se existem responsáveis, eles devem ter os seus atos e omissões tipificados clara e concretamente e, assim, penalizados. (Idem, ibid., p. 11)

Com base nessas considerações, podemos sistematizar da seguinte forma as diferentes concepções sobre o objeto de uma LRE, conforme a amplitude do seu propósito. Formalmente, uma LRE de conteúdo máximo poderia, na verdade, ser produzida como uma lei complementar de regulamentação do regime de cooperação educacional (Constituição, art. 23, inciso V, § único), que especificasse atribuições de cada ente federado e a responsabilidades dos gestores:

\section{Tabela 2}

Conteúdo máximo e conteúdo mínimo de uma Lei de Responsabilidade Educacional

\begin{tabular}{|l|l|}
\hline $\begin{array}{l}\text { LRE: conteúdo mínimo } \\
\text { (responsabilidade jurídica) }\end{array}$ & $\begin{array}{l}\text { LRE: conteúdo máximo } \\
\text { (concepção ampliada) }\end{array}$ \\
\hline - Definição dos bens jurídicos protegidos; & $\begin{array}{l}\text { - Detalhamento do regime de atribuições } \\
\text { para a garantia do direito e o alcance das } \\
\text { metas do PNE; }\end{array}$ \\
- definição dos sujeitos responsabilizáveis; & $\begin{array}{l}\text { - definição das atribuições na colaboração } \\
\text { federativa; }\end{array}$ \\
$\begin{array}{l}\text { ou funciona da natureza da responsabiliza- } \\
\text { - procedimento de apuração da responsa- } \\
\text { bilidade jurídica. }\end{array}$ & $\begin{array}{l}\text { - definição de mecanismos de gestão demo- } \\
\text { crática e de controle social para a apuração } \\
\text { das responsabilidades. }\end{array}$ \\
\hline
\end{tabular}


É evidente que mesmo a opção pelo conteúdo mínimo não estaria isenta de polêmicas. Além do escopo geral da lei, a questão política fundamental é definir a composição de cada um de seus elementos essenciais. Por exemplo, a discussão sobre a responsabilização dos docentes se colocaria na definição dos sujeitos responsabilizáveis, podendo ganhar sentidos diferentes com a ampliação do conteúdo.

Ao invés de se falar em apuração tecnocrática da responsabilidade, com o sentido de controle exclusivamente burocrático sobre o trabalho docente, poder-se-ia estipular formas de construção de responsabilidade negociada e participativa, com base na gestão democrática e no controle social e com a participação dos pares, tendo como propósito o fortalecimento da colaboração de interesse público.

\section{A responsabilidade universal e o acesso à justiça pela via da ação civil pública}

Ao se discutir a criação de uma LRE, é preciso tomar em conta que um dos princípios básicos do Estado Democrático de Direito Republicano é a responsabilidade universal. Ou seja, todos são responsabilizáveis por seus atos (excluídos, evidentemente, os inimputáveis e os civilmente irresponsáveis), inclusive o próprio Estado, uma vez que ninguém pode agir fora dos limites do Direito. ${ }^{4}$

Essa é a base da chamada responsabilidade civil dos particulares e também do regime jurídico da responsabilidade civil do Estado, previsto no artigo $37, \S 6^{\circ}$, da Constituição. Sua exigibilidade independe de lei expressa, pois "a própria noção de Estado de Direito impõe, como seu consectário natural, a responsabilidade pública por atos danosos a terceiros. (...) se não há sujeitos fora do Direito, não há sujeitos irresponsáveis; se o Estado é um sujeito de direitos, o Estado é responsável" (Mello, 2005, p. 929-930). O requisito para a responsabilidade é a existência de um direito (bem juridicamente protegido), cujo dano ou violação enseja responsabilização civil.

Portanto, não cabe e não existe irresponsabilidade absoluta em nosso contexto. Como a educação é um direito fundamental amplamente protegido pela Constituição, mesmo inexistindo previsão específica, haveria responsabilidade educacional (do Estado, dos servidores e dos particulares) decorrente do princípio da responsabilidade civil universal.

O Estado pode ser responsabilizado civilmente por ato danoso à integridade física ou intelectual de alguém, sendo obrigado a indenizá-lo. Há responsabilidade estatal, por exemplo, em relação às crianças que estão sob sua guarda nas unidades de ensino. Pode-se ainda cogitar em tese a responsabilização do Estado por não atender à demanda por matrícula ou mesmo pela não garantia de padrões básicos de qualidade, como a não designação de professores em número suficiente. 
Nesses casos, tanto a supressão da omissão como o reconhecimento da responsabilidade teriam que ser reconhecidos no Judiciário, através de ações individuais ou da Ação Civil Pública (ACP), proposta na defesa de direitos educacionais coletivos. Digiácomo (2004, p. 352) ressalta a amplitude conferida à ACP na legislação:

(...) presta-se não apenas para garantir a oferta de ensino fundamental e demais níveis de ensino, mas também, como dissemos anteriormente, para assegurar que a educação básica, como um todo, atenda aos princípios e objetivos estabelecidos na Constituição Federal (com destaque para "garantia do padrão de qualidade") e LDB.

Para o reconhecimento da responsabilidade do Estado na esfera civil, portanto, basta a definição do direito e a existência de mecanismos eficazes de exigibilidade jurídica, cabendo ao Judiciário arbitrar as obrigações a serem implementadas e os eventuais valores de reparação. A ACP pode ser esse instrumento, desde que superadas as resistências do sistema de justiça, identificadas por Silveira (2010). Esta autora aponta também a ampliação significativa na utilização dos instrumentos jurídicos para a defesa do direito à educação, desde que entrou em vigor o Estatuto da Criança e do Adolescente (ECA), com destaque para o papel das ações civis públicas propostas pelo Ministério Público.

Nesse contexto é que precisa ser analisado o PL n. 8.039/10, do governo, que propõe modificação na Lei da ACP para criar a modalidade ação civil pública de responsabilidade educacional. Conforme identifica Cury (2011, p. 14) "essa alteração não inova em termos de exigibilidade e compromisso. Ela reitera o que, de certo modo, já está posto na legislação". Isso porque a ACP já contempla todos os interesses e direitos difusos ou coletivos, havendo inclusive previsão expressa em relação ao direito à educação no artigo 208 do ECA.

Se na teoria, na lei e na prática a criação de tal modalidade é, no limite, desnecessária do ponto de vista formal, passamos a cogitar dois reais propósitos para o projeto: o primeiro, implícito, seria nominar um instrumento específico capaz de mobilizar o sistema de justiça para a defesa da educação e o acompanhamento dos convênios interfederativos; o segundo propósito, explícito no projeto, seria tentar excluir as metas de qualidade aferidas nos testes padronizados do campo de judicialização da educação, sinalizando que não há intenção de apoiar iniciativas de responsabilização vinculadas a tais metas. Nesse sentido, pode ser entendido como um projeto de antirresponsabilidade educacional, em resposta às pressões por responsabilização.

Para a ampliação da exigibilidade jurídica da educação, mais do que reformas pontuais na legislação processual, seria efetiva a definição objetiva do conteúdo jurídico do padrão de qualidade (Constituição, art. 206, VII), estabelecendo-se os insumos e gastos obrigatórios. 
O PL n. 8.039/10 não propõe uma LRE, pois esta não disciplinaria a responsabilidade jurídica do Estado como pessoa jurídica, que está limitada ao aspecto cível e, por princípio, prescinde de regulamentação. Seu objeto por definição é a responsabilidade pessoal das autoridades políticas, dos servidores públicos e dos demais agentes educacionais. As grandes questões que se colocam são: responsabilidade pessoal de quem, por quais atos ou omissões?

\section{Crime de responsabilidade educacional e infração político-administrativa}

O regime jurídico atual da responsabilidade educacional, enquanto responsabilidade pessoal,tem expressão no $\S 2^{\circ}$ do artigo 208 da Constituição que, ao tratar dos deveres estatais em relação ao ensino, determina: “O não oferecimento do ensino obrigatório pelo Poder Público, ou sua oferta irregular, importa responsabilidade da autoridade competente" (Brasil, 2012).

Trata-se, neste caso, de responsabilidade política, exclusiva das autoridades estatais. A LDB explicita esse tema no parágrafo $4^{\circ}$ do artigo $5^{\circ}$ : “Comprovada a negligência da autoridade competente para garantir o oferecimento do ensino obrigatório, poderá ela ser imputada por crime de responsabilidade" (Brasil, 1996).

A responsabilidade política já vinha regulamentada na Lei n. 1.079, de 1950, que trata dos crimes de responsabilidade do presidente da República, dos ministros de Estado, dos ministros do Supremo Tribunal Federal, do procurador-geral da República, dos governadores de estado e de seus secretários; ; e no Decreto-Lei n. 201, de 1967, que trata da responsabilidade penal e das infrações político-administrativas de prefeitos e vereadores. $\mathrm{O}$ crime de responsabilidade das autoridades federais e estaduais e a infração política dos prefeitos não são tipos penais comuns (Konzen, 2000), mas verdadeiro crime político (infração político-administrativa), decorrente do mau exercício das atribuições constitucionais e legais por eles assumidas.

Essas normas foram recepcionadas pela Constituição com algumas modificações, entre elas a ampliação decorrente da previsão de crime de responsabilidade educacional (art. 208, $\S 2^{2}$ ). Tal dispositivo tem grande valor jurídico-político, pois expressa a densidade desse direito na Constituição e aponta a necessidade de uma proteção mais efetiva. Ao incorporar a ideia ampla de oferta irregular, ademais, a Constituição abre a possibilidade de se reconhecer como objeto de responsabilização a omissão na garantia do padrão de qualidade, além da não garantia de acesso. Também há previsão legal de crime de responsabilidade por atraso na liberação dos recursos vinculados ao ensino (LDB, art. 69, § 6º).

Em relação especificamente ao direito à educação, houve ampliação recente para incorporar os casos de descumprimento das obrigações de complementação da 
União ao Fundo de Manutenção e Desenvolvimento da Educação Básica e de Valorização dos Profissionais da Educação (Fundeb) (Constituição, ADCT, art. 60, XI, com a redação da Emenda n. 53/06). Há ainda a possibilidade de responsabilização educacional indireta através da Lei de Responsabilidade Fiscal (LRF) (LC n. 101/2000), pelo descumprimento das vinculações legais e pela má gestão dos recursos públicos (respectivamente, artigos $8^{\circ}$, § único, e 73). Ou ainda por ato de improbidade administrativa (Constituição, art. 85, inciso V), ou recusa a implementar decisão judicial protetiva do direito à educação (Lei n. 1.079/50, art. $4^{\circ}$, inciso VIII).

Os PLs n. 4.020/06, 1.680/07, 413/11 e 450/11 tratam do tema da responsabilidade política por descumprimento das metas de universalização e qualidade, aferidas como insumos e resultados nos exames nacionais, propondo sua equiparação ao crime de responsabilidade por violação patente ao exercício dos direitos individuais e sociais (Lei n. 1.70/50, art. $7^{\circ}$, IX) e à infração político-administrativa, no caso dos prefeitos, por omissão na defesa dos direitos e interesses do município (Decreto-Lei n. $201 / 67$, art. $4^{\circ}$, VIII).

Em todos os casos, trata-se de reconhecer infrações que podem levar à perda do cargo e à inabilitação para o exercício da função pública pelo prazo de até oito anos. A legislação assegura a qualquer cidadão o direito de apresentar acusação por crime de responsabilidade. No entanto, como se trata de infração de natureza política, seu julgamento fica a cargo do órgão do Poder Legislativo competente. E justamente por ser regido pelas regras do sistema político é que esses instrumentos de responsabilidade educacional têm efeito mais simbólico que prático, ou seja, são mais eficazes na direção das condutas que na responsabilização de fato.

Isso porque, mais que o respeito ou não ao direito à educação da população, sua aplicação depende fundamentalmente da situação de sustentação política nas casas legislativas. Portanto, apesar de sua importância para a democracia, o regime da responsabilidade política das autoridades tem evidentes limitações procedimentais, que o tornam de difícil aplicação fora dos contextos de crise política generalizada. Nesse sentido, é ineficaz quando pensamos em uma legislação que efetivamente possibilite monitorar o cumprimento dos deveres estatais em matéria de ensino e a real possibilidade de aplicação de penalidades nos casos de omissão.

\section{Responsabilidade por improbidade administrativa e responsabilidade funcional}

Outra modalidade de responsabilização se dá através do reconhecimento da improbidade administrativa, sendo que há parcial coincidência entre as condutas definidas de forma genérica como crime de responsabilidade e os chamados atos de improbidade. Não há na Lei de Improbidade Administrativa (Lei n. 8.429/92) menção 
específica ao direito à educação, o que não afasta a possibilidade de aplicação dessa norma a desvios, atos de corrupção e mesmo omissão flagrante na garantia de direitos relacionados ao ensino, como de fato ocorre, por exemplo, em relação à gestão fraudulenta de recursos vinculados aos programas suplementares federais, merenda e transporte escolar.

A responsabilidade por improbidade administrativa também é de natureza civil, sem prejuízo que os mesmos atos possam configurar crimes comuns contra a administração pública, puníveis segundo a lei penal. Pode provocar "a suspensão dos direitos políticos, a perda da função pública, a indisponibilidade dos bens e o ressarcimento ao erário, na forma e gradação previstas em lei, sem prejuízo da ação penal cabível" (Constituição, art. 37, §4º). Diferentemente da responsabilidade política, no entanto, que é exclusiva das autoridades, a improbidade administrativa pode ser cometida por qualquer agente público, seja ele funcionário público da administração direta, indireta ou fundacional; servidor temporário ou mesmo particulares (Lei n. 8.429/92, artigos 2ํㅜ e $3^{\circ}$ ).

Segundo esta legislação, após denúncia, que pode ser apresentada por qualquer pessoa, a apuração se dá tanto na esfera administrativa, nos órgãos de controle interno da administração, como nos tribunais de contas, e no Ministério Público. Cabe a este último, ou à pessoa jurídica cujo patrimônio foi lesado, propor a ação pública de improbidade administrativa, que é decidida no Judiciário.

As formas de apuração e julgamento da improbidade administrativa têm potencial de torná-la mais efetiva no combate aos desvios e omissões, levando, por um caminho menos tortuoso, ao reconhecimento da responsabilidade civil, funcional e política dos agentes públicos. Nesse sentido, a previsão expressa de improbidade com base na responsabilidade educacional tem maior potencial de influenciar as políticas públicas e a conduta dos gestores, quando comparada ao crime de responsabilidade ou à infração político-administrativa.

Os Projetos n. 4.020/06, 1.680/07, 413/11 e 450/11 propõem que o descumprimento das metas neles estabelecidas, entre elas a evolução nos resultados aferidos nos exames nacionais, seja caracterizado como ato de improbidade administrativa atentatório aos princípios da administração pública, nos termos da legislação específica - Lei n. 8.429/92 -, aplicando-se ainda penas em dobro em relação ao estabelecido nessa lei.

Já os Projetos n. 247/11 e 600/11, com idêntico teor, buscam ampliar a incidência do instituto da improbidade unicamente para as situações de não aplicação dos recursos vinculados à manutenção e desenvolvimento do ensino (MDE), ou sua aplicação irregular. Também preveem que a reincidência em tais atos deve levar à inelegibilidade dos responsáveis, nos termos da chamada Lei da Ficha Limpa (Lei Complementar n. 135/10). 
Não há grandes polêmicas quanto ao caminho adotado pelos Projetos n. 247/11 e 600/11, uma vez que se trata de antiga reivindicação dos atores do campo educacional, inconformados com a situação de impunidade de gestores que descumprem as vinculações constitucionais. Seguindo o exemplo da LRF, Cury (2011, p. 9) entende que este seria o caminho a ser seguido pela LRE:

(...) estabeleceria metas de conduta para os gestores dos sistemas públicos de ensino. Agentes públicos que deixassem de aplicar o percentual mínimo da receita das receitas tributárias na manutenção e desenvolvimento da educação poderiam ter que responder por improbidade administrativa.

Esse mecanismo de responsabilização poderia também ser estendido para outros deveres educacionais presentes na Constituição, como a universalização do ensino obrigatório, a implantação dos planos de carreira e a edição do Plano Nacional de Educação, para citar alguns exemplos de obrigações que são atribuídas às autoridades políticas.

A polêmica se coloca a partir da definição do padrão de qualidade como exigência de evolução nos resultados aferidos nos testes nacionais e, principalmente, com a ampliação do objeto da responsabilização para esse campo e a inclusão dos servidores da educação entre os responsabilizáveis.

No caso da improbidade, como já mencionado, todo e qualquer agente público pode ser responsabilizado e punido segundo a Lei, ou seja, com a aprovação do previsto nos Projetos n. 4.020/06, 1.680/07, 413/11 e 450/11, estaria aberta, ao menos em tese, a possibilidade de enquadramento de servidores do magistério em ato de improbidade por, de alguma forma, induzirem ou concorrerem com descumprimento de metas acadêmicas. É bem verdade que essa tese pouco convencional precisaria ser admitida no Judiciário, mas o caminho estaria aberto.

Talvez o maior risco, no entanto, como alerta Freitas (2011), decorra do reflexo de tamanha pressão por responsabilização nas legislações locais, cuja regulamentação cabe a municípios e estados. É praticamente decorrência lógica que atos de improbidade administrativa também sejam reconhecidos como infrações de natureza administrativo-funcional.

Ressalte-se que, do ponto de vista dos servidores públicos, a principal dimensão é justamente a responsabilidade administrativo-funcional, por descumprimento dos deveres relacionados especificamente ao cargo ou função pública que ocupam. A previsão dos atos ou omissões puníveis normalmente se dá nos estatutos jurídicos das categorias, em cada esfera de governo, ou em normas de conduta específicas. Um elemento importante é que as punições são processadas e aplicadas no âmbito administrativo, podendo variar de uma advertência até a demissão do funcionário. 
Contra o mito da irresponsabilidade é importante reconhecer a responsabilidade educacional de natureza administrativo-funcional dos servidores do magistério, cujos estatutos próprios preveem um conjunto de punições por atos contrários ao bom funcionamento dos sistemas de ensino, como faltas injustificadas, corrupção ou atuação em desacordo com as obrigações assumidas. Para o magistério, há inclusive incumbências legais expressamente previstas na LDB (art. 13), que se refletem nas legislações locais.

Hoje, portanto, o que se está discutindo e implantando em diferentes redes de ensino são reformas para estabelecer premiações ou punições relacionadas ao desempenho dos estudantes e escolas nos exames nacionais de larga escala. Em muitos casos, tais reformas são promovidas com a difusão do referido mito da irresponsabilidade dos docentes, com o que se busca legitimação na opinião pública.

A novidade não é a responsabilidade pessoal dos docentes, mas sua vinculação às metas acadêmicas e à difusão da lógica de mercado na educação pública, estimulando-se a competição entre redes e escolas, como parece ser o intuito dos projetos que estabelecem a divulgação em larga escala dos resultados de cada unidade de ensino (PL n. 1.747/11, 1.915/11 e 2.604/11), cuja expressão mais radical é a proposta de obrigar a própria escola a divulgar, na entrada do prédio, seu resultado no Ideb (PL n. 3.066/11).

\section{Responsabilidade pessoal dos pais, tutores ou responsáveis}

Por fim, para complementar esse panorama da responsabilidade educacional em discussão, há a possibilidade de responsabilização penal, cível e administrativa dos pais ou responsáveis legais pelo descumprimento dos deveres relacionados à promoção da educação escolar das crianças. A responsabilidade, nessas situações, é decorrência da obrigatoriedade escolar, que exige o estabelecimento de alguma sanção punitiva para o caso de descumprimento, não necessariamente de natureza penal.

O crime de abandono intelectual consiste em "deixar, sem justa causa, de prover instrução primária de filho em idade escolar" (Código Penal, art. 246), entendendo-se hoje o ensino primário como equivalente ao ensino fundamental. Uma vez que a norma penal não pode ser interpretada de forma extensiva, hoje haveria uma defasagem entre essa previsão e a ampliação da obrigatoriedade, que passou a incorporar toda a faixa etária de 4 a 17 anos de idade.

Os projetos de lei em discussão na Comissão Especial que buscam ampliar a responsabilidade educacional dos agentes privados, no entanto, não propõem modificação para abranger na previsão de abandono intelectual toda a atual faixa de 
obrigatoriedade. O PL n. 8.042/10 estende a autoria desse crime aos detentores de guarda ou tutela, enquanto o PL n. 1.256/07 propõe ampliar seu objeto para incorporar omissões dos pais ou responsáveis em acompanhar e corrigir aspectos relacionados à sua vida escolar.

O caminho da criminalização de pais ou responsáveis, em sua grande maioria vítimas da exclusão educacional brasileira, é marca de uma visão autoritária e discriminatória contra as camadas populares. Deve-se, portanto, promover a responsabilidade jurídica não pela via criminal, mas através de punições administrativas e, sobretudo, medidas de apoio e proteção.

Nesse sentido, os Projetos n. 247/11 e 600/11 propõem a modificação do artigo $6^{\circ}$ da LDB e do artigo 249 do ECA para ampliar a responsabilidade administrativa dos pais ou responsáveis em relação à matrícula, incorporando todas as séries obrigatórias. Também preveem a ampliação das medidas de proteção do ECA (art. 101), incorporando o encaminhamento para matrícula obrigatória no ensino médio.

\section{Conclusões}

Amplos setores sociais, de diferentes orientações políticas, vêm defendendo a ampliação das normas definidoras do direito à educação e sua maior proteção no sistema de justiça. Tão evidente quanto o aparente consenso retórico em torno da necessidade de maior proteção legal é a divergência política sobre o conteúdo das normas, a dimensão do dever do Estado no financiamento e regulamentação do ensino, o lugar da iniciativa privada, o conceito de valorização dos trabalhadores da educação pública e o sentido da gestão democrática, só para citar alguns temas que historicamente dividem opiniões. Hoje, a principal disputa sobre o conteúdo das normas gira em torno das concepções de qualidade e de responsabilidade educativa.

O que está em jogo, portanto, é nada menos que a concepção de qualidade educacional que prevalecerá enquanto regulamentação do "padrão" a ser assegurado como determinação constitucional (art. 206, VII). O risco é que novas normas venham a provocar retrocessos na concepção de direito à educação como um direito humano, consolidando a redução de seu conteúdo à noção de direito à aprendizagem. $\mathrm{Ou}$, usando outros termos, que sobre o impulso das legítimas demandas populares por direito à educação imponham-se concepções privatistas, tecnicistas e autoritárias.

Aprendizagem de todos e de cada um, respeitadas suas singularidades, é o resultado que se espera de uma escola de qualidade, mas não pode ser entendida como o único bem jurídico a ser protegido pelo direito à educação. Dimensões como a garantia de insumos, como professores valorizados e espaços adequados de convívio; e de processos educacionais, que possibilitem o exercício dos direitos humanos 
na educação, assim como a formação cidadã e o exercício prático da cidadania, são igualmente relevantes.

Essa concepção ampliada de qualidade leva a que se privilegiem os aspectos do financiamento e dos insumos educacionais, que devem ser assegurados na legislação como requisitos indispensáveis. Privilegia-se a aposta na gestão e avaliação democráticas como instrumentos de garantia da qualidade socialmente referenciada, que passa a ser exigível na medida em que são asseguradas pelo Estado as condições elementares de funcionamento das instituições escolares. Requer, por consequência, a substituição do enfoque das atuais avaliações externas, que deveriam incorporar essencialmente os aspectos dos insumos e dos processos, complementados por indicadores de desempenho e de sucesso escolar. ${ }^{6}$ Ou seja, substituiríamos os indicadores de aprendizagem por indicadores de direito à educação.

A concepção de responsabilidade, nessa perspectiva, é de caráter essencialmente político e coletivo, e tem como objeto o cumprimento das determinações em termos de financiamento da educação pública em cada ente federado, a valorização dos trabalhadores da educação nos termos da legislação, a garantia de oportunidades de aprendizagem e de insumos básicos em todas as unidades públicas do país. Em alguma medida, como vimos, esta concepção já se encontra regulamentada na legislação e é inclusive aplicada pelos tribunais, o que não nos exime de reconhecer que mereceria melhor definição jurídica em alguns pontos.

Tal perspectiva sobre a qualidade do ensino e sobre a responsabilidade por sua garantia, no entanto, vem esbarrando nas exigências de ampliação dos dispêndios educacionais públicos, que exigiria, por exemplo, a implantação do custo aluno-qualidade em todas as redes de ensino. Também esbarra, por consequência, nos profundos desequilíbrios federativos e na ausência de regulamentação do regime de cooperação e colaboração. Uma LRE, em sentido ampliado (ver Quadro 2), poderia ser pensada como uma lei complementar que instituísse o regime de cooperação e, ao mesmo tempo, determinasse detalhadamente as responsabilidades políticas de cada esfera de governo e respectivos gestores. Uma norma desse tipo também resolveria o problema da fragmentação das legislações.

No contexto em que, de um lado, se coloca o clamor por melhoria da qualidade do ensino e, de outro, persiste o subfinanciamento educacional e a indefinição no regime de cooperação, ganha força a agenda de gestão escolar. Com esse enfoque, adotam-se mecanismos de quase-mercado, com o estímulo à competição interna nos sistemas de ensino e entre redes e escolas, em muitos casos acompanhada da privatização por dentro da gestão do ensino público, tanto através de empresas privadas que oferecem material apostilado e assessoria técnica às redes de ensino, como por meio dos institutos empresariais, que passam a influenciar fortemente os rumos das 
políticas educacionais. Em comum nesses processos está a promessa de melhoria da qualidade do ensino, entendida fundamentalmente como melhoria nos resultados de avaliação sistêmica.

Nesse sentido, é importante destacar que também está em discussão neste momento (tanto no Substitutivo do relator do PL n. 8.035/2010 como em Grupo de Trabalho criado no âmbito do Ministério da Educação) a definição das chamadas expectativas de aprendizagem ou expectativas de direito à aprendizagem (Cedes, 2012), que, uma vez instituídas, ofereceriam o necessário lastro jurídico de exigibilidade das metas acadêmicas, além de oferecer, do ponto de vista do mercado, a necessária previsibilidade quanto à mercadoria-aprendizagem a ser contratada. Afinal, a questão que se coloca tem a ver com o princípio da necessária anterioridade da lei punitiva, segundo a qual alguém somente pode ser punido por ato ou omissão tipificado como passível de punição no momento em que ocorre.

Tanto nos projetos de lei analisados neste ensaio como no debate sobre o novo PNE, há o objetivo de transformação do Ideb de política de governo em política de Estado, abrindo-se a possibilidade de vincular a conduta dos gestores ao atingimento das metas de desempenho estipuladas em nível nacional. Com a definição das expectativas de aprendizagem, complementarmente, almeja-se estipular em norma nacional as matrizes de referência dos testes, que deixando de ser meras decisões discricionárias do Ministério da Educação, através do Inep, passam a ser exigíveis como (uma perspectiva de) padrão nacional de qualidade. Legitimados juridicamente, Ideb e expectativas passam a constituir objeto de responsabilização dos gestores. Esta responsabilidade, uma vez que estamos falando de aprendizagem, função essencial da escola e do magistério, tenderá a recair sobre estes e sobre os demais trabalhadores da educação. Como expressou um importante interlocutor: "A lei de responsabilidade vai da merendeira ao Ministro"(Seminário, 2008).

Como demonstramos neste ensaio, é essa a perspectiva que predomina nas proposições em discussão no Legislativo, que buscam redefinir a responsabilidade educacional para incluir como objeto de responsabilização o fracasso nos testes e como sujeitos responsabilizáveis, em última instância, os trabalhadores da educação. A concepção de responsabilidade deixa de ser predominantemente política (do agente político) e coletiva e passa a ser funcional (do funcionário) e individual, enfocando, em última instância, a responsabilização dos trabalhadores da educação e das escolas.

Cabe questionar se esta não seria a verdadeira agenda hegemônica por trás do atual ciclo de reformas jurídicas, ou seja, se não estaríamos consolidando uma perspectiva reducionista de qualidade da educação e aumentando a pressão por responsabilização do magistério, tudo sob um manto retórico de participação e democratização. 


\section{Notas}

1. Em agosto de 2008, com o objetivo de impulsionar esse debate, foi realizado na Câmara dos Deputados o Seminário "Ética e Responsabilidade na Educação: compromissos e resultados", organizado pela Comissão de Educação e Cultura, Todos pela Educação e Representação da Unesco no Brasil.

2. Há ainda outro sentido para o termo responsabilidade no Documento Final da Conae, não relacionado aos deveres estatais, mas à corresponsabilidade da família com a educação das crianças e adolescentes e ainda ao debate sobre a medida de responsabilidade do indivíduo por seu desempenho escolar.

3. Além da proposta de uma visão compreensiva de responsabilidade educacional, as resoluções da Conae rejeitam explicitamente a responsabilização direta dos educadores.

4. O poder imperial é, por natureza, irresponsável em termos jurídicos. A Constituição brasileira de 1824, por exemplo, previa expressamente que o Imperador era inviolável, sagrado e não estava sujeito a responsabilidade alguma (art. 99).

5. O processo por crime de responsabilidade mais emblemático na história recente do Brasil se deu contra o ex-presidente Collor, que, mesmo após renunciar ao mandato, foi condenado e afastado temporariamente da vida política.

6. Essa concepção está na base do Custo Aluno-Qualidade Inicial (CAQi), amplamente referendado na Conae (2010), incorporado ao Substitutivo do relator ao PL n. 8.035/2010 (PNE) e já aprovado no Conselho Nacional de Educação através do Parecer CNE/CEB n. 08/2010.

\section{Referências}

BOBBIO, N. Da estrutura à função: novos estudos de teoria do direito. Barueri: Manole, 2007.

BROOKE, N. O futuro das políticas de responsabilização educacional no Brasil. Cadernos de Pesquisa, São Paulo, v. 36, n. 128, p. 377-401, maio/ago. 2006.

BRASIL. Constituição (1988). Constituição da República Federativa do Brasil. Brasília, DF: Planalto, 2012. Disponível em: <www.planalto.gov.br>. Acesso em: 28 mar. 2012.

BRASIL. Lei n. 9.394, de 20 de dezembro de 1996, que dispõe sobre as diretrizes e bases da educação nacional. Brasília, DF: Senado Federal, 1996.

BRASIL. Projeto de Lei n. 7.420, de 2006, da deputada Raquel Teixeira, que dispõe sobre a qualidade da educação básica e a responsabilidade dos gestores públicos na sua promoção. Brasília, DF: Câmara dos Deputados, 2006. Disponível em: <www. camara.gov.br>. Acesso em: 12 mar. 2012.

CONFERÊNCIA NACIONAL DE EDUCAÇÃO (CONAE), 2010, Brasília, DF. Documento final. Brasília, DF: MEC, 2010.

CURY, C.R.J. Lei de responsabilidade educacional. Brasília, DF: Fórum Nacional de Educação, 2011. Disponível em: <fne.mec.gov.br>. Acesso em: 22 fev. 2012. 
CURY, C.R.J.; FERREIRA, L.A. A judicialização da educação. In: FERREIRA, L.A. Temas de direito à educação. São Paulo: Imprensa Oficial do Estado; Escola Superior do Ministério Público, 2010. p. 53-94.

DIGIÁCOMO, M.J. Instrumentos jurídicos para garantia do direito à educação. In: LIBERATI, W.D. (Org.). Direito à educação: uma questão de justiça. São Paulo: Malheiros, 2004. p. 273-373.

FREITAS, L.C. Lei de responsabilidade educacional? ComCiência: revista eletrônica de jornalismo científico, Campinas, v. 132, out. 2011. Disponível em: <http://www. comciencia.br>. Acesso em: 22 fev. 2012.

GOMES, C.A. Fundamentos de uma lei de responsabilidade educacional. Brasília, DF: Unesco, 2008. (Debates, 10). Disponível em: <unesdoc.unesco.br>. Acesso em: 22 fev. 2012.

GRAU, E.R. A ordem econômica na Constituição de 1988. 14. ed. São Paulo: Malheiros, 2010.

KONZEN, A. O direito à educação escolar. In: KONZEN, A. et al. Pela justiça na educação. Brasília, DF: MEC; Fundescola, 2000. p. 659-668.

MELLO, C.A.B. Curso de Direito Administrativo. 19. ed. São Paulo: Malheiros, 2005.

OLIVEIRA, R.P. Estado e política educacional no Brasil: desafios do século XXI. 2006. 121f. Tese (Livre-docência) - Faculdade de Educação, Universidade de São Paulo, São Paulo.

OLIVEIRA, R.P.; ARAUJO, G. Qualidade do ensino: uma nova dimensão da luta pelo direito à educação. Revista Brasileira de Educação, Rio de Janeiro, n. 28, p. 5-23, 2005.

PINTO, J.M.R. A política recente de fundos para o financiamento da educação e seus efeitos no pacto federativo. Educação E Sociedade, Campinas, v. 28, n. 100, p. 877-897, 2007.

SEMINÁRIO EXPECTATIVAS DE APRENDIZAGEM E O PNE, 2012, Brasília, DF. Relatório síntese. Brasília, DF, 2012. Disponível em: <http://www.cedes.unicamp.br/ Expectativas_de_Aprendizagem.pdf $>$. Acesso em: 8 abr. 2012.

SEMINÁRIO Internacional discute Lei de Responsabilidade Educacional. Brasília, DF: Câmara dos Deputados; Comissão de Educação e Cultura, 2008. Disponível em: <http:// www2.camara.gov.br/atividade-legislativa/comissoes/comissoes-permanentes/cec/ noticias-raiz/seminario-internacional-discute-lei-de>. Acesso em: 5 maio 2012. 
SILVEIRA, A.D. O direito à educação de crianças e adolescentes: análise da atuação do Tribunal de Justiça de São Paulo. 2010. 303f. Tese (Doutorado em Educação) - Faculdade de Educação, Universidade de São Paulo, São Paulo.

Recebido em 7 de maio de 2012.

Aprovado em 2 de junho de 2012. 